\title{
A Ship Collision Analysis Program Based on Upper Bound Solutions and Coupled with a Large Rotational Ship Movement Analysis Tool
}

\author{
Hervé Le Sourne, ${ }^{1}$ Nicolas Besnard, ${ }^{2}$ \\ Cedric Cheylan, ${ }^{3}$ and Natacha Buannic ${ }^{2}$ \\ ${ }^{1}$ Mechanical Engineering Department (LE2M), ICAM Nantes Campus, \\ 35 Avenue du champ de Manœuvres, 44470 Carquefou, France \\ 2 PRINCIPIA, 1 rue de la Noé, 44321 Nantes Cedex 3, France \\ ${ }^{3}$ Hull and Accommodation Structures Department, DCNS Ingénierie SNS, Rue Choiseul, \\ 56311 Lorient, France
}

Correspondence should be addressed to Hervé Le Sourne, herve.lesourne@icam.fr

Received 19 January 2012; Revised 15 March 2012; Accepted 27 March 2012

Academic Editor: Armin Troesch

Copyright (c) 2012 Hervé Le Sourne et al. This is an open access article distributed under the Creative Commons Attribution License, which permits unrestricted use, distribution, and reproduction in any medium, provided the original work is properly cited.

This paper presents a user-friendly rapid prediction tool of damage to struck and striking vessels in a ship collision event. To do this, the so-called upper bound theorem is applied to calculate internal forces and energies of any substructure involved in the ships crushing process. At each increment of indentation, the total crushing force is transmitted to the external dynamics MCOL program, which calculates the global ship motion correction by solving the hydrodynamic force equilibrium equations. As a first step, the paper gives a brief description of the upper bound method originally developed for perpendicular collisions and recently enhanced for oblique ones. Then, the theory developed in MCOL program for large rotational ship movements is detailed. By comparing results obtained with and without MCOL, the importance of hydrodynamic effects is highlighted. Some simulation results are compared with results provided by classical nonlinear finite element calculations. Finally, by using the developed analytical tool, which mixes internal and external dynamics, different crushing scenarios including oblique collisions are investigated and the influence of some collision parameters like longitudinal and vertical impact location, impact angle, and struck ship velocity is studied.

\section{Introduction}

Amongst all the loads that have to be expected for the design of ship, the collision between two vessels is one of the most important. This is especially the case for dry cargo vessels and tankers, which are devoted to the transport of oil, petrol, or other toxic products. Such vessels have to be designed carefully because they may induce a severe pollution of oceans, such as 
during oil slicks, for example. These environmental disasters have to be avoided, principally because of their consequences on marine biotopes, but also because they are economically and humanly expensive. Moreover, the reputation of the companies involved in these ecological degradations can be severely damaged.

To deal properly with ship collision, it is of course possible to use nonlinear finite element methods. Nevertheless, at the predesign stage, such approaches are rather prohibitive because of the time required to model and simulate collisions involving large-size structures. This is especially true when a large number of scenarios have to be investigated. Therefore, simplified methods (empirical or analytical) have been developed in order to verify the resistance of ships submitted to impacts [1].

Minorsky [2] was the first to establish a simplified formulation of the ship resistance to collision. His formula was based on statistical data and was only valid for large energy collisions. Since this pioneer work, some more refined analytical developments have been performed in order to assess the impact resistance of various structural elements of ships. These individual members may be classified in three main categories

(i) the web girders, such as decks, stringers, transverse frame, transverse bulkheads, bottom floors, and longitudinal girders; the common property of all these structural elements is that they will deform like a concertina during an impact;

(ii) the side panels, which are used to model the behavior of the outer and the inner shell plating (if any) in collision analysis;

(iii) the intersection elements, which are located at the junction between vertical and horizontal structural members.

In the literature, various authors have already developed theoretical models of all the previous components involved in naval architecture. For example, the crushing resistance of web girders was theoretically and experimentally studied by Wierzbicki and CulbertsonDriscoll [3], Wang and Ohtsubo [4], Simonsen [5], and Zhang [6]. Each of them developed analytical formulations that may be used to assess rapidly the resistance of web girder submitted to an impact loading. Hong and Amdahl [7] summarized and compared all these various approaches. They also developed a very refined expression to properly evaluate the ultimate crushing resistance of girders.

The individual behavior of ship side panels has been investigated in detail by Wang $[8,9]$ and Zhang [6]. Some references are also available to evaluate the resistance of metal plates after rupture, when they are submitted to tearing and cutting. For example, these phenomena have been studied by Wang and Ohtsubo [10], Zhang [11], Wierzbicki [12], and Zheng [13]. In the particular case of stiffened panels subjected to lateral load, the developments performed by Paik [14], Cho and Lee [15], or Ueda et al. [16] constitute a very accurate basis for deriving analytical estimation of the resistance of such structural members.

Finally, the crushing resistance of the intersection between vertical and structural members has been analyzed in detail by Amdahl [17] and Zhang [6].

The previous brief literature review shows that some results are already available to deal with a simplified approach of ship collisions, which would be time- and cost-effective in the stage of predesigning large ships for example. This can be achieved by modeling the architecture of ships with very large-sized structural units and a limited number of nodal points. Using the literature references mentioned above, closed-form analytical formulations of the resistance of each unit may be derived. Then, by combining properly the individual resistances, it is possible to obtain a global evaluation of the ability of a ship to withstand an impact with another vessel. 
This basic idea was initially suggested by Ueda and Rashed [18], who called it the idealized structural unit method (ISUM). Lützen et al. [19] developed a similar approach called the superelement method (SEM), in which the ship is divided into large structural components (the so-called superelements), whose resistance is assessed by making use of the abovementioned literature references. More recently, Buldgen et al. [20] extended the method to oblique collision cases by developing new superelements.

Internal mechanics must be coupled with an external dynamics solver dedicated to simulate the global ship motion, taking into account the forces due to the surrounding water but there are very few analysis procedures where the internal and external dynamics are completely coupled. One of these, named SIMCOL, was developed by Brown [21], and coupled internal/external mechanic results were compared successfully with time simulation results.

Initially, a first version of a rigid body dynamic program named MCOL was developed by Mitsubichi and included in the nonlinear finite element code LS-DYNA. The difference of displacements between two colliding ships may lead to large amplitude rotational motions for the struck ship and the viscous hydrodynamic forces, which appear during sway, roll, and yaw movements, may be great. For example, large rolling movement occurs when the bulb of a surface ship impacts a submarine superstructure. Therefore, MCOL program has been improved by PRINCIPIA in order to take into account large rotational movements driven by the crushing force and the forces due to surrounding water (added mass, wave damping, and restoring forces) and to introduce viscous damping effects. The new version of MCOL program was then implemented in LS-DYNA and used to numerically model the large rotational movement of submarines impacted by surface ships [22].

The purpose of this paper is to present the analytical tool named SHARP, which couples internal and external mechanics. The theory developed in an adapted version of MCOL program is detailed in this paper, with the objective to calculate at each time step the global ships motions correction by taking into account all the above-mentioned hydrodynamic effects.

\section{Modeling of Internal Mechanics}

\subsection{Theoretical Basis}

The method is based on the so-called "upper bound theorem," which, according to Jones [23], states that "if the work rate of a system of applied loads during any kinematically admissible collapse of a beam is equated to the corresponding internal energy dissipation rate, then that system of loads will cause collapse, or incipient collapse, of the structure."

In order to apply this theorem, the external and the internal energy rates are first evaluated. The first one is simply given by

$$
\dot{E}_{\mathrm{ext}}=F \cdot \dot{\delta},
$$

where $F$ is the required resistance of the superelement, $\delta$ is the penetration of the striking ship in the structure, and $E_{\text {ext }}$ is the external energy dissipated by crushing the superelement, and where the dot "." is used to designate a time derivative. 


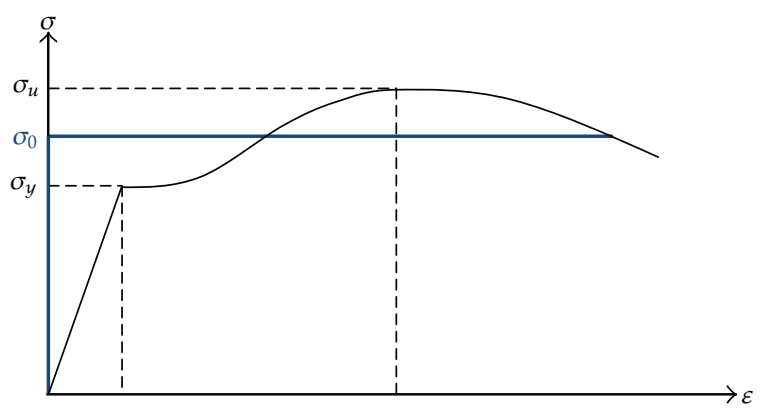

Figure 1: Example of stress-strain curve for mild steel.

Then, the internal energy rate for a solid body may be written as

$$
\dot{E}_{\mathrm{int}}=\iiint_{V} \sigma_{i j} \cdot \dot{\epsilon}_{i j} \cdot d V
$$

where $V$ is the volume of the solid body, $\sigma_{i j}$ is the stress tensor, and $\dot{e}_{i j}$ is the strain rate tensor. In order to obtain a closed-form expression of the collision resistance, some simplifications have to be made, unless (2.2) would be too complicated to be solved analytically. For purpose of simplicity, the following hypotheses are made.

(i) The material of the element is assumed to be perfectly rigid, as shown in Figure 1. The flow stress $\sigma_{0}$ is usually given by (note that when the flow stress is defined by (2.3), the solution is strictly not an upper bound solution; it will be the case for $\left.\sigma_{0}=\sigma_{y}\right)$

$$
\sigma_{0}=\frac{\sigma_{y}+\sigma_{u}}{2}
$$

where $\sigma_{y}$ is the static yield stress and $\sigma_{u}$ is the static ultimate stress. By doing such hypothesis, the elastic part of the deformation and the strain rate effect are neglected. Note that when using expression (2.3),

(ii) The first contribution to the total internal energy rate is the bending one. It is assumed here that flexional effects are confined in a certain number $m$ of plastic hinge lines. Therefore, bending internal energy is written as

$$
\dot{E}_{b}=M_{0} \sum_{k=1}^{m} \dot{\theta}_{k} l_{k}
$$

where $M_{0}$ is the fully plastic bending moment and $\theta_{k}$ and $l_{k}$ are, respectively, the rotation and the length of the hinge plastic number $k$. 
(iii) The second contribution to the total energy rate is the membrane one. In the case of a plate with a thickness $t_{p}$, this energy is given by

$$
\dot{E}_{m}=t_{p} \iint_{A} \sigma_{i j} \cdot \epsilon_{i j} \cdot d A,
$$

where $A$ is the area of the deforming plate. If we assume a plane-stress state, the use of Von Mises yield criterion leads to

$$
\dot{E}_{m}=\frac{2 \sigma_{0} t_{p}}{\sqrt{3}} \iint_{A} \sqrt{\dot{\epsilon}_{X X}^{2}+\dot{\epsilon}_{Y Y}^{2}+\dot{\epsilon}_{X Y}^{2}+\dot{\epsilon}_{X X} \dot{\epsilon}_{Y Y}} \cdot d X d Y .
$$

Finally, to obtain the total energy rate, the previous contributions given by (2.4) and (2.6) are summed:

$$
\dot{E}_{\mathrm{int}}=\dot{E}_{b}+\dot{E}_{m}
$$

The described procedure seems to be rather simple, but the most difficult part in the equations above remains the calculation of the strain rate tensor $\dot{e}_{i j}$. This is done by choosing displacements fields, which are close enough to those observed on impact trials or, in the absence of test, on numerical simulations. The problem with the upper bound method is that it can lead to overestimate the resistance if the displacements fields are not chosen carefully so as to be in good accordance with reality.

\subsection{Struck Side Crushing Resistance Evaluation}

\subsubsection{Superelements Derived for Right-Angle Collisions}

As a first step, it is assumed that the bow of the striking vessel is perfectly rigid. The modeling of the internal mechanics is then performed by dividing the struck ship into different superelements. During the perpendicular impact, each of them will be submitted to important deformations, principally in the plastic domain. By use of closed-form expressions, it is then possible to estimate the crushing energy dissipated by each of these macrocomponents. Consequently, for a given penetration of the striking vessel, the total energy involved by the internal mechanics is simply obtained by summation over all the crushed superelements.

In case of a perpendicular impact, according to Lützen et al. [19], the architecture of the struck ship is basically modeled with the four following superelements.

(i) The first superelement (Figure 2) is a rectangular plate simply supported on its four edges. During a right-angle impact, this plate will suffer large out-of-plane deflections dominated by a membranous behaviour (see, Zhang [6], e.g.,). The rupture is supposed to occur when the deformations exceed a threshold value. Typically, this superelement is used to model inner and outer side plating and longitudinal bulkheads.

(ii) The second superelement (Figure 3) is a rectangular plate simply supported on three edges. The last edge is free and is submitted to an in-plane load during a 


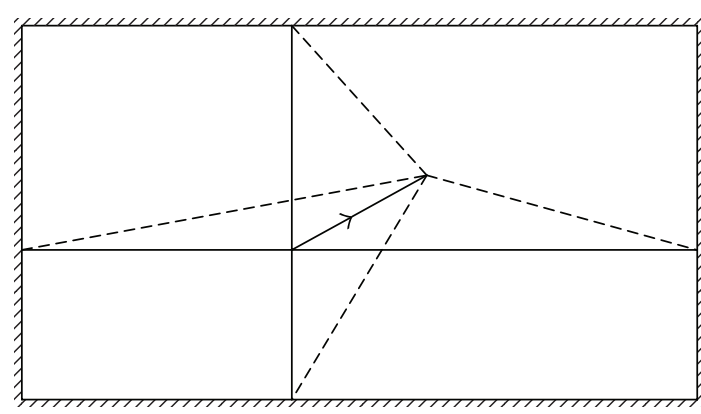

- - - Deformed configuration

W/, Simply supported edges

Figure 2: Plate subjected to out-of-plane deformation.

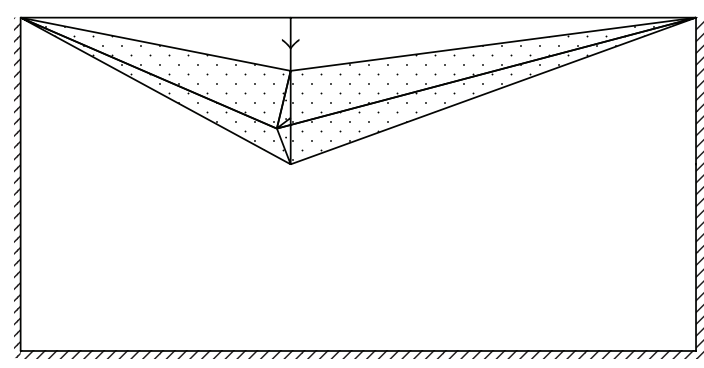

"W/, Simply supported edges

Fold under formation

Figure 3: Illustrations for the second superelement.

perpendicular collision. According to Pedersen et al. [24], such an impacted plate will form successive folds until fracture. As suggested by Wierzbicki [12], the rupture occurs by tearing along the supported edges, which allows the plate to deform like a concertina. Typically, this superelement is used to model decks, transverse bulkheads, web girders, frames, bottom and inner-bottom.

(iii) The third superelement (Figure 4(a)) is a beam loaded by a perpendicular transverse force. During a collision, it is supposed to collapse in two different phases. In the first step, it assumed that a plastic mechanism involving three plastic hinges occurs. After that, in a second step, the beam is behaving more like a plastic string. This superelement is principally used to model small stiffeners like longitudinals.

(iv) The last superelement (Figure 4(b)) concerns X-T-L-form intersections. During a collision, they are assumed to be crushed axially until they are completely deformed along their initial length. They are useful to model the junction of vertical and horizontal structural members.

With all the above superelements is associated a closed-form expression, which allows to calculate the energy dissipated by each of them during a right-angle collision scenario. To 


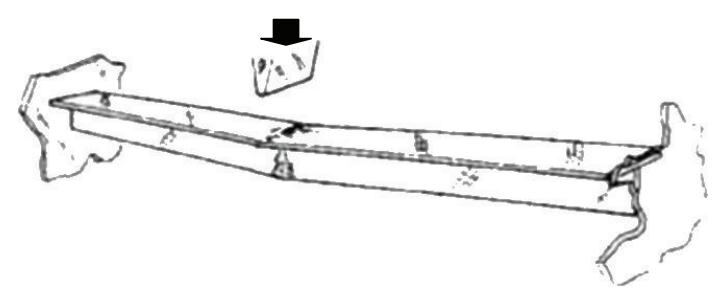

(a) Beam impacted eccentrically

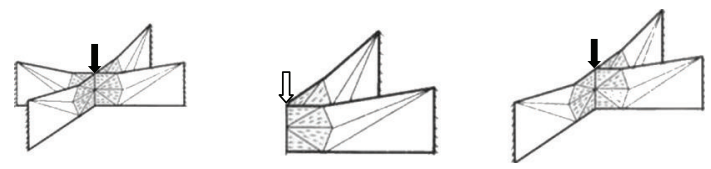

(b) X-L-T-form intersection

Figure 4: Illustrations for the third and fourth superelements—the figures are extracted from [6].

obtain the total energy involved for a given penetration, it is sufficient to add the individual contribution of all the crushed superelements. This is a rather approximate method because it neglects the interactions that may happen in reality between the various structural members. Nevertheless, comparisons with experiments and finite element simulations have shown a sufficiently good outcome $[25,26]$ so that the method finally leads to a reasonable estimation of the struck ship crushing force $\mathbf{F}_{1}$ under the hypothesis of a perfectly rigid striking bow.

\subsubsection{Generalization of the Method for Oblique Collisions}

In order to deal successfully with nonperpendicular collisions, six different superelements have been developed and the corresponding crushing force derivations are detailed in [20].

The first superelement (SE1) (Figure 5(a)) is used to assess the resistance of a plate simply supported on its four edges and submitted to an out-of-plane impact occurring with a certain angle, which may be different from $90^{\circ}$ (perpendicular impact).

The second superelement (SE2) (Figure 5(b)) is a vertical plate simply supported on three edges and free on the last one. The collision happens on this unsupported edge, with an angle maybe different from $90^{\circ}$. The third superelement (SE3) is similar to the previous one (Figure 5(c)), but this time the impact does not happen on the free edge, it is rather located inside the structure. It is important to distinguish between SE2 and SE3 because the deformation modes are different.

The fourth superelement (SE4) is different from the three previous ones in the sense that it is not a plated structure (Figure 5(d)). This time, the model is dealing with a beam submitted to a nonsymmetrical impact, occurring with a certain angle. The beam is supposed to have a T-cross section and is assumed to be clamped at both extremities.

The fifth superelement (SE5) is absolutely similar to the X-T-L-form intersections already described in Section 3.2 (see Figures 5(e) and 4(b)). The only difference is the collision scenario, which is assumed to happen obliquely.

The last superelement (SE6) is a horizontal plate, simply supported on three edges and remaining free on the last one. In fact, the structure is completely similar to the vertical one considered in SE2 and SE3, but the impact scenario is different. The collision is assumed to occur with a certain angle in the plane of the horizontal plate (see Figure 5(f)). 


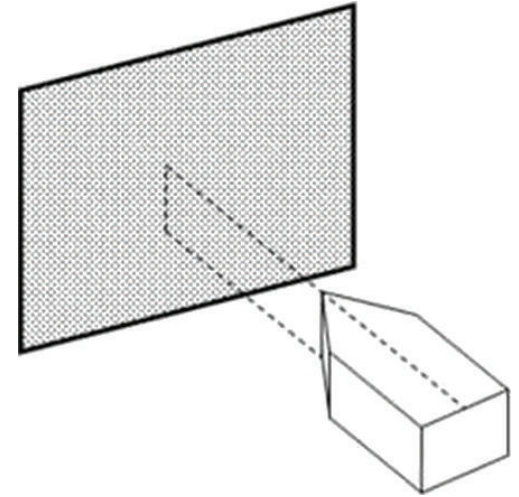

(a) SE1

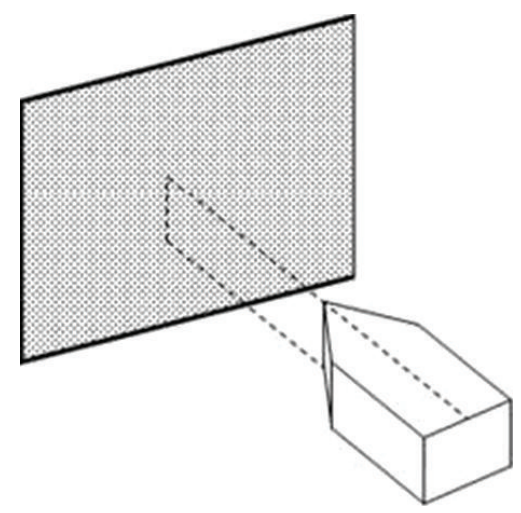

(c) SE3
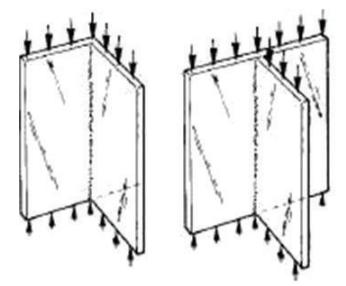

(e) SE5

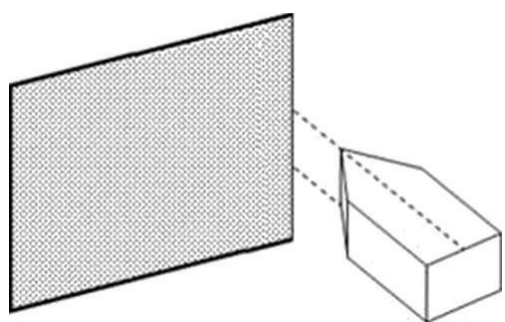

(b) SE2

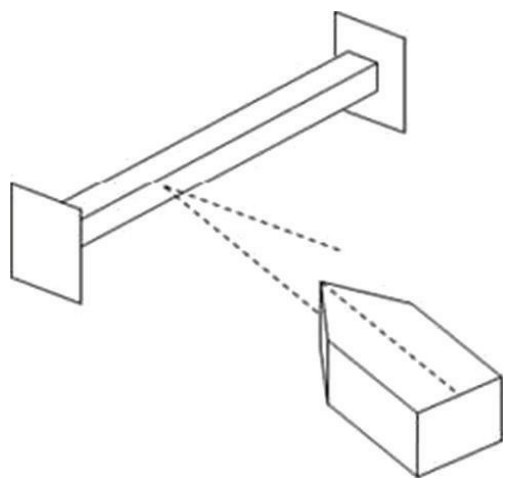

(d) SE4
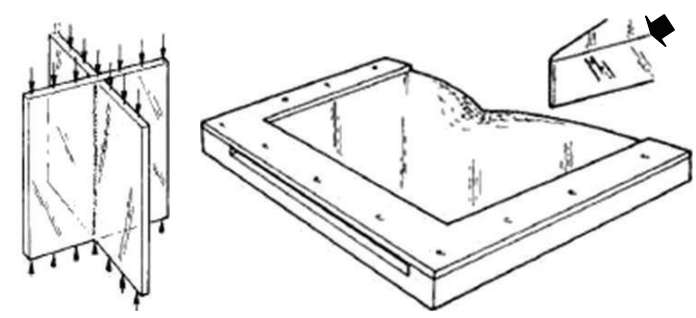

(f) SE6

Figure 5: Description of superelements for oblique collisions-(e) and (f) are extracted from [6].

With the six superelements described here above, it is possible to treat the case of nonperpendicular collisions between two ships. These elements are sufficient to model the individual behaviour of the principal components forming the structure of classical ships. By establishing the law giving the evolution of the crushing resistance with respect to the penetration (see [20] for more details), these superelements allow an analytical estimation of the collision resistance. 


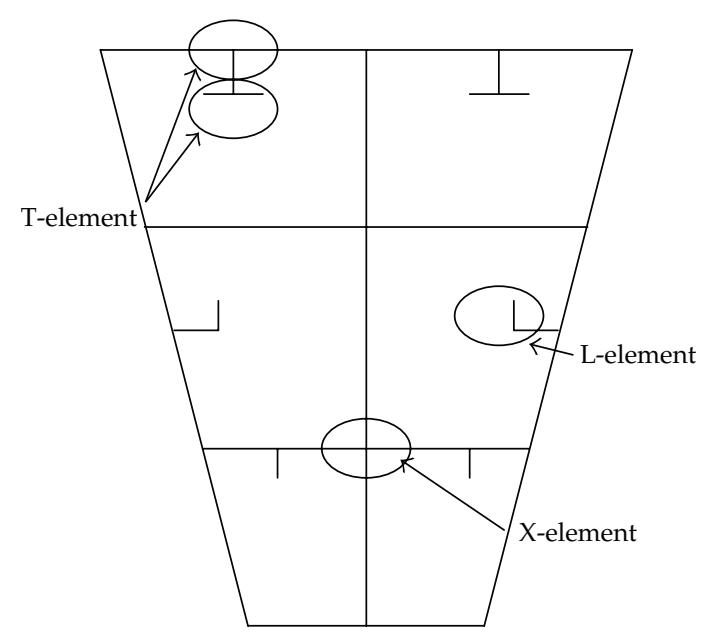

Figure 6: Description of basic elements of a ship bow.

\subsection{Striking Bow Crushing Resistance Calculation}

Let us assume now that the striking bow is deformable during its impact against a rigid struck side. The method for determination of the bow crushing force was developed by Simonsen and Ocakli [26] and is based on a modification of Amdahl's method [17]. This method has been established on the basis of theoretical considerations of energy dissipated during plastic deformation of basic elements such as angles, T-sections, and cruciforms, which compose a ship bow section (Figure 6). The formula for the average crushing strength is given by

$$
\sigma_{c}=2.42\left[\frac{n_{A T} t^{2}}{A}\right]^{0.67}\left[0.87+1.27 \frac{n_{c}+0.31 n_{T}}{n_{A T}}\left(\frac{A}{\left(n_{c}+0.31 n_{T}\right) t^{2}}\right)^{0.25}\right]^{0.67} .
$$

The total crushing force is obtained by multiplying this strength by the associated crosssectional area of the deformed material: $F_{2}=\sigma_{c} A$ with $\sigma_{c}$ being the average crushing strength of bow, $\sigma_{0}$ the flow stress, $t$ the average plate thickness of the cross-section under consideration, $A$ the cross-sectional area of deformed steel material, $n_{c}$ the number of cruciforms, $N_{T}$ the number of T-sections, and $N_{A T}$ the number of angle and T-sections.

\section{Modeling of External Mechanics}

\subsection{Rigid Body Large Rotation Dynamics}

For each ship, the program MCOL uses two reference frames. The first one is a body-fixed frame with its origin being the centre of mass of the ship and with an $x$-axis along the forward axis of the ship, a starboard $y$-axis, and a downward $z$-axis (Figure 7). The second frame is an earth-fixed frame defined as the initial position of the body-fixed frame. The motion of a ship is defined by its roll, pitch, and yaw (Eulerian angles $\phi, \theta$, and $\Psi$ ) and by the translation 


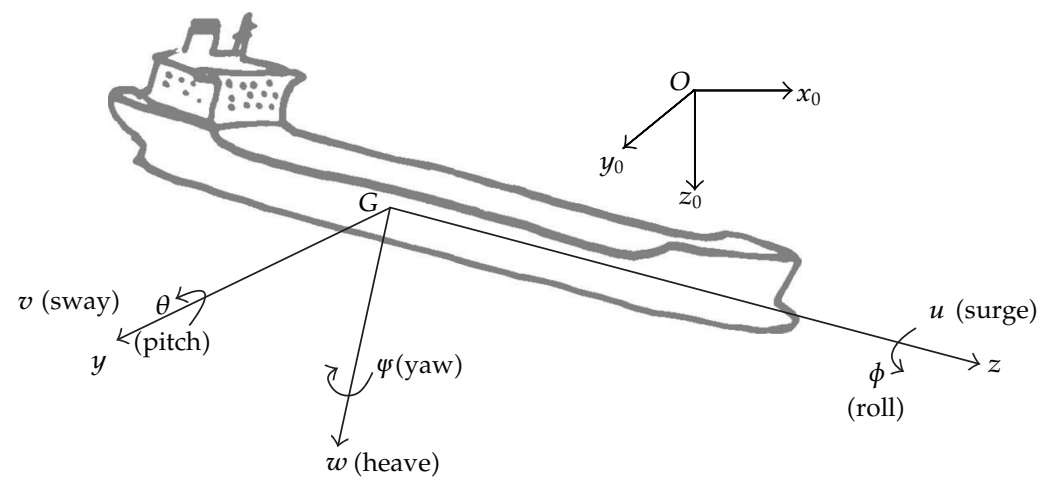

Figure 7: Body-fixed and earth-fixed references frames.

of its centre of mass from its initial position. Hence, the general motion is described with the following conventions:

$$
\begin{aligned}
& \mathbf{x}=\left(x_{0 G}, y_{0 G}, z_{0 G}, \phi, \theta, \Psi\right)^{T} \\
& \mathbf{y}=(u, v, w, p, q, r)^{T}=\left(\mathbf{v}^{T}, \boldsymbol{\omega}^{T}\right)^{T} \\
& \mathbf{f}=(X, Y, Z, K, M, N)^{T}
\end{aligned}
$$

where $\mathbf{x}$ denotes the earth-fixed position of the ship centre of mass and the Eulerian angles, $\mathbf{y}$ the body-fixed components of the velocity $\mathbf{v}$ of the centre of mass and of the angular velocity vector $\boldsymbol{\omega}$, and $\mathbf{f}$ the body-fixed components of the forces and of the moments relative to the centre of mass acting on the body.

An orthogonal matrix $\mathbf{R}$ with a positive determinant can uniquely describe the orientation of a rigid body, which rotates freely in space. For the representation of motion using Eulerian angles, the rotation matrix that transforms the vector components from the bodyfixed frame to the earth-fixed frame can be expressed in the following way:

$$
\mathbf{R}=\left[\begin{array}{lll}
r_{11} & r_{12} & r_{13} \\
r_{21} & r_{22} & r_{23} \\
r_{31} & r_{32} & r_{33}
\end{array}\right] \text { with }\left\{\begin{array}{l}
r_{11}=\cos \theta \cos \psi, \\
r_{12}=\sin \phi \sin \theta \cos \psi-\cos \phi \sin \psi, \\
r_{12}=\cos \phi \sin \theta \cos \psi+\sin \phi \sin \psi, \\
r_{21}=\cos \theta \sin \psi, \\
r_{22}=\sin \phi \sin \theta \sin \psi+\cos \phi \cos \psi, \\
r_{23}=\cos \phi \sin \theta \sin \psi-\sin \phi \cos \psi, \\
r_{31}=-\sin \theta, \\
r_{32}=\sin \phi \cos \theta \\
r_{33}=\cos \phi \cos \theta .
\end{array}\right.
$$

This matrix results from three consecutive rotations. The precise order in which they are applied leads to different definitions of the parameterization. In the marine vehicle roll, pitch, and yaw conventions, the first rotation is around $\vec{z}_{0}$-axis and transforms the $\left(\vec{x}_{0}, \vec{y}_{0}, \vec{z}_{0}\right)$ earthfixed frame into $\left(\vec{n}, \vec{t}, \vec{z}_{0}\right)$. The second rotation is applied around the new vector $\vec{t}$ and 
transforms the $\left(\vec{n}, \vec{t}, \vec{z}_{0}\right)$ frame into $\left(\vec{x}, \vec{t}, \vec{z}_{1}\right)$. Finally the third rotation is applied around $\vec{x}$ to transform the frame $\left(\vec{x}, \vec{t}, \vec{z}_{1}\right)$ into the body-fixed frame $(\vec{x}, \vec{y}, \vec{z})$ :

$$
\begin{aligned}
\vec{t} & =-\sin \psi \vec{x}_{0}+\cos \psi \vec{y}_{0}, \\
\vec{x} & =\cos \theta \vec{n}-\sin \theta \vec{z}_{0}, \\
\vec{n} & =\cos \psi \vec{x}_{0}+\sin \psi \vec{y}_{0}, \\
\vec{y} & =\cos \phi \vec{t}+\sin \phi \vec{z}_{1}, \\
\vec{z}_{1} & =\sin \theta \vec{n}+\cos \theta \vec{z}_{0}, \\
\vec{z} & =-\sin \phi \vec{t}+\cos \phi \vec{z}_{1} .
\end{aligned}
$$

With such a definition of three independent rotations, the angular velocity vector can be simply expressed as

$$
\vec{\omega}=\dot{\psi} \vec{z}_{0}+\dot{\theta} \vec{t}+\dot{\phi} \vec{x}
$$

This leads to a nonlinear transformation between the body-fixed velocity components and the time derivatives of the position and the Eulerian angles:

$$
\dot{\mathbf{x}}=\mathbf{J y},
$$

where the transformation matrix $\mathbf{J}$ is such that

$$
\mathrm{J}=\left[\begin{array}{ll}
R & 0 \\
0 & Q
\end{array}\right], \quad \text { where } Q=\left[\begin{array}{ccc}
1 & \sin \phi \tan \theta & \cos \phi \tan \theta \\
0 & \cos \phi & -\sin \phi \\
0 & \frac{\sin \phi}{\cos \theta} & \frac{\cos \phi}{\cos \theta}
\end{array}\right]
$$

The motion of a rigid body with respect to a body-fixed rotating reference frame with its origin the centre of mass is given by Newton's law:

$$
\begin{gathered}
m\left(\dot{\vec{v}}_{G}+\vec{\omega} \times \vec{v}_{G}\right)=\vec{f}_{R G}, \\
\mathbf{I}_{G} \dot{\vec{\omega}}+\vec{\omega} \times\left(\mathbf{I}_{G} \vec{\omega}\right)=\vec{m}_{R G},
\end{gathered}
$$

where $m$ is the mass of the rigid-body, $\mathbf{I}_{G}$ is the inertia tensor with respect to the centre of mass $G$ in the body-fixed reference frame, $\vec{f}_{R G}$ the forces applied to the body, and $\vec{m}_{R G}$ the moment of those forces with respect to $G$. Then, the equations of the rigid body can be expressed in the body-fixed frame with the general form

$$
\mathbf{M}_{R B} \dot{\mathbf{y}}+\mathbf{G}_{R B} \mathbf{y}=\mathbf{F}_{R B} .
$$


Here, $\mathbf{M}_{R B}$ is the constant and positive rigid body inertia matrix:

$$
\mathbf{M}_{R B}=\left[\begin{array}{cccccc}
m & 0 & 0 & 0 & 0 & 0 \\
0 & m & 0 & 0 & 0 & 0 \\
0 & 0 & m & 0 & 0 & 0 \\
0 & 0 & 0 & I_{x x} & -I_{x y} & -I_{x z} \\
0 & 0 & 0 & -I_{x y} & I_{y y} & -I_{y z} \\
0 & 0 & 0 & -I_{x z} & -I_{y z} & I_{z z}
\end{array}\right]
$$

where $I_{x x}, I_{y y}$, and $I_{z z}$ are the moments of inertia in relation to the $x_{-}, y^{-}$, and $z$-axes of the body-fixed frame and $I_{x y}, I_{x z}$, and $I_{y z}$ are the products of inertia.

$\mathrm{G}_{R B}$ is the skew-symmetrical gyroscopic matrix:

$$
\mathbf{G}_{R B}=\left[\begin{array}{cccccc}
0 & 0 & 0 & 0 & m w & -m v \\
0 & 0 & 0 & -m v & 0 & m u \\
0 & 0 & 0 & 0 & -m u & 0 \\
0 & m w & 0 & 0 & -I_{3} & I_{2} \\
-m w & 0 & m u & I_{3} & 0 & -I_{1} \\
m v & -m u & 0 & -I_{2} & I_{1} & 0
\end{array}\right],
$$

where

$$
\begin{aligned}
& I_{1}=I_{x z} p+I_{y z} q-I_{z z} r, \\
& I_{2}=I_{x y} p-I_{y y} q+I_{y z} r, \\
& I_{3}=I_{x x} p-I_{x y} q-I_{x z} r .
\end{aligned}
$$

\subsection{Hydrodynamic Models Used in MCOL}

The forces and moments acting on colliding ships can be separated into contact forces and moments due to the obstacle $F_{C}$ and hydrodynamic forces and moments due to the surrounding fluid. On rest water, the latter are usually separated into the inertia forces (added mass) $\mathbf{F}_{\mathbf{A}}$, the restoring forces (buoyancy-gravity) $\mathbf{F}_{\mathbf{H}}$, the viscous forces (drag and lift) $\mathbf{F}_{\mathbf{V}}$, and the wave forces $\mathbf{F}_{\mathrm{W}}$.

\subsubsection{Added Inertia}

The acceleration inertia forces are assumed to be essentially the result of inertia of the fluid. The complete set of inertial hydrodynamic forces (added masses) for an arbitrarily shaped body in the standard ship maneuvering terminology has been given by Imlay [27] and can be expressed in the body-fixed frame as

$$
\mathbf{F}_{A}=-\mathbf{M}_{A} \dot{\mathbf{y}}-\mathbf{G}_{A} \mathbf{y},
$$

where the added inertia matrix $\mathbf{M}_{A}$ is symmetrical and constant for a submerged body below the wave-affected zone and depends on the vertical position of the centre of mass $z_{0 G}$, the 
roll angle $\phi$, and the trim angle $\theta$ for a surface ship. For a surface ship moving at a given forward speed, $\mathbf{M}_{A}$ is not symmetrical and also strongly varies with the radiated wave frequency. Therefore, in the latter case, $\mathbf{M}_{A}$ will represent only the constant added mass for infinite frequency $\mathbf{M}(\infty)$ and the wave effects will be included with wave damping in a single memory term. In any case, $\mathbf{M}_{A}$ is usually expressed as follows:

$$
\mathbf{M}_{A}=-\left[\begin{array}{ccc|ccc}
X_{\dot{u}} & X_{\dot{v}} & X_{\dot{w}} & X_{\dot{p}} & X_{\dot{q}} & X_{\dot{r}} \\
Y_{\dot{u}} & Y_{\dot{v}} & Y_{\dot{w}} & Y_{\dot{p}} & Y_{\dot{q}} & Y_{\dot{r}} \\
Z_{\dot{u}} & Z_{\dot{v}} & Z_{\dot{w}} & Z_{\dot{p}} & Z_{\dot{q}} & Z_{\dot{r}} \\
\hline K_{\dot{u}} & K_{\dot{v}} & K_{\dot{w}} & K_{\dot{p}} & K_{\dot{q}} & K_{\dot{r}} \\
M_{\dot{u}} & M_{\dot{v}} & M_{\dot{w}} & M_{\dot{p}} & M_{\dot{q}} & M_{\dot{r}} \\
N_{\dot{u}} & N_{\dot{v}} & N_{\dot{w}} & N_{\dot{p}} & N_{\dot{q}} & N_{\dot{r}}
\end{array}\right],
$$

and the gyroscopic matrix $\mathbf{G}_{A}$ is the skew-symmetric matrix such that

$$
\mathbf{G}_{A}=\left[\begin{array}{cccccc}
0 & 0 & 0 & 0 & -a_{3} & a_{2} \\
0 & 0 & 0 & a_{3} & 0 & -a_{1} \\
0 & 0 & 0 & -a_{2} & a_{1} & 0 \\
0 & -a_{3} & a_{2} & 0 & -a_{6} & a_{5} \\
a_{3} & 0 & -a_{1} & a_{6} & 0 & -a_{4} \\
-a_{2} & a_{1} & 0 & -a_{5} & a_{4} & 0
\end{array}\right],
$$

where

$$
\begin{aligned}
& a_{1}=X_{\dot{u}} u+X_{\dot{v}} v+X_{\dot{w}} w+X_{\dot{p}} p+X_{\dot{q}} q+X_{\dot{r}} r, \\
& a_{2}=Y_{\dot{u}} u+Y_{\dot{v}} v+Y_{\dot{w}} w+Y_{\dot{p}} p+Y_{\dot{q}} q+Y_{\dot{r}} r, \\
& a_{3}=Z_{\dot{u}} u+Z_{\dot{v}} v+Z_{\dot{w}} w+Z_{\dot{p}} p+Z_{\dot{q}} q+Z_{\dot{r}} r, \\
& a_{4}=K_{\dot{u}} u+K_{\dot{v}} v+K_{\dot{w}} w+K_{\dot{p}} p+K_{\dot{q}} q+K_{\dot{r}} r, \\
& a_{5}=M_{\dot{u}} u+M_{\dot{v}} v+M_{\dot{w}} w+M_{\dot{p}} p+M_{\dot{q}} q+M_{\dot{r}} r, \\
& a_{6}=N_{\dot{u}} u+N_{\dot{v}} v+N_{\dot{w}} w+N_{\dot{p}} p+N_{\dot{q}} q+N_{\dot{r}} r .
\end{aligned}
$$

\subsubsection{Restoring Forces and Moments}

The gravitational and buoyant forces are written as $W=m g$ and $B=\rho g \nabla$, where $g$ is the gravitational acceleration, $\rho$ is the density of water, and $\nabla$ is the volume of the displaced water. They act along the $z_{0}$-axis of the earth-fixed reference frame through the centre of gravity and the centre of buoyancy. Therefore, the components of the restoring forces and moments in the body-fixed reference frame are

$$
\mathbf{F}_{H}=\left[\begin{array}{c}
-\sin \theta(W-B) \\
\sin \phi \cos \theta(W-B) \\
\cos \phi \cos \theta(W-B) \\
\left(z_{B} \sin \phi \cos \theta-y_{B} \cos \phi \cos \theta\right) B \\
\left(x_{B} \cos \phi \cos \theta+z_{B} \sin \theta\right) B \\
\left(-y_{B} \sin \theta-x_{B} \sin \phi \cos \theta\right) B
\end{array}\right]
$$


This relation is very efficient for a submerged body when the water displacement and the position of the centre of buoyancy are constant. Nevertheless, those values depend on $z_{0 G}$ as well as on the roll angle $\phi$ and the trim angle $\theta$ for a surface ship. Therefore, restoring forces and moments are expressed as a linear function of displacements relative to a given reference position and attitude $\mathbf{x}_{\text {ref }}$ :

$$
\mathbf{F}_{H}=-\left[\begin{array}{cc}
\mathbf{R}^{* T} & \mathbf{0} \\
\mathbf{0} & \mathbf{R}^{* T}
\end{array}\right] \mathbf{K}\left(\mathbf{x}-\mathbf{x}_{\text {ref }}\right)+\mathbf{F}_{H \text { ref }}
$$

In this expression, the components $\mathbf{F}_{H \text { ref }}$ of the restoring forces and moments in the bodyfixed frame corresponding to the reference position and attitude $\mathbf{x}_{\mathrm{ref}}$ are given by (3.16).

$\mathbf{K}$ is the restoring stiffness matrix defined in the earth-fixed frame such that

$$
\mathbf{K}=\rho g\left[\begin{array}{cccccc}
0 & 0 & 0 & 0 & 0 & 0 \\
0 & 0 & 0 & 0 & 0 & 0 \\
0 & 0 & A_{W} & A_{W} y_{W} & -A_{W} x_{W} & 0 \\
0 & 0 & A_{W} y_{W} & J_{W x} & -J_{W x y} & 0 \\
0 & 0 & -A_{W} x_{W} & -J_{W x y} & J_{W y} & 0 \\
0 & 0 & 0 & 0 & 0 & 0
\end{array}\right]
$$

with $A_{W}$ being the area of water plane of the ship, $x_{W}$ and $y_{W}$ the body-fixed co-ordinates of the centre, and $J_{W x}, J_{W y}$, and $J_{W x y}$ the corresponding inertia components of this area.

$\mathbf{R}^{*}$ is the rotation matrix from the reference water plane fixed frame:

$$
\mathbf{R}^{*}=\left[\begin{array}{ccc}
\cos \theta_{\text {ref }} & \sin \phi_{\text {ref }} \cos \theta_{\text {ref }} & \cos \phi_{\text {ref }} \sin \theta_{\text {ref }} \\
0 & \cos \phi_{\text {ref }} & -\sin \phi_{\text {ref }} \\
-\sin \theta_{\text {ref }} & \sin \phi_{\text {ref }} \cos \theta_{\text {ref }} & \cos \phi_{\text {ref }} \cos \theta_{\text {ref }}
\end{array}\right]
$$

\subsubsection{Wave Memory Effects}

During a transient motion a ship generates waves that produce hydrodynamic damping forces with a memory effect. It results in forces and moments with memory effect usually written in the body-fixed frame as follows $[28,29]$ :

$$
\mathbf{F}_{W}=-\int_{0}^{t} \mathbf{G}(\tau)(\mathbf{y}(t-\tau)-\mathbf{y}(0)) d \tau
$$

where the matrix $\mathbf{G}$ is given by

$$
G(\tau)=\frac{2}{\pi} \int_{0}^{\infty} \mathbf{C}(\omega) \cos (\omega \tau) d \omega
$$

Here, the matrix $\mathbf{C}$ contains the hydrodynamic damping coefficients depending on the wave pulsations $\omega$. In our ship collision studies, these coefficients as well as the added mass and restoring stiffness matrices have been computed for each ship by the sea-keeping code 
DIODORE [29] based on the boundary integral method. The numerical calculation of $\mathbf{F}_{W}$ is detailed in [22].

\subsubsection{Viscous Forces and Moments}

Viscous effects are the most critical elements of ship manoeuvring mathematical formulation, and they dramatically change the flow pattern in slow speed manoeuvres compared with "normal" manoeuvres. At small drift angles, the ship hull can be regarded as a lifting surface with the drift angle taking the role of the conventional angle of attack. At larger drift angles, there is no convenient way of prescribing either the location or the strength of the shed vorticity, and a significant part of the forces are of a "cross-flow-drag" nature. The shedding of the vortices from the body seems inevitabe to imply a separation of the boundary layer. But the meaning of separation and its distribution along the hull, its variation as a function of drift angle, its dependence on the Reynolds number, and even indications of its presence are not clear-cut in naval hydrodynamics.

For this reason, and assuming that there is no large-scale separation or ventilation giving rise to vorticity "memory" effects of fluid motion, we assume that the hydrodynamic forces at any instant depend only on the instantaneous velocities of the ship and that they can be represented by two simple summations depending on the magnitude of the drift angle. At large drift angles, the side force is dominated by cross flow, and the viscous damping reduces to

$$
\vec{f}_{v}=-\frac{1}{2} \rho \sum_{i} C_{D i} A_{i}\left|\vec{v}_{C_{i}} \cdot \vec{n}_{i}\right|\left(\vec{v}_{C_{i}} \cdot \vec{n}_{i}\right) \vec{n}_{i}
$$

where the summation operates on dragging surfaces such as keel, rudders, and the ship itself. Each surface $\left(S_{i}\right)$ is defined by a drag coefficient $C_{D}$, its area $A$, and the position $\left(x_{c}, y_{c}, z_{c}\right)$ of the centre of the area in the body-fixed frame.

At moderate drift angle, it is assumed that lift damping prevails and can be expressed as follows:

$$
\vec{f}_{v}=-\frac{1}{2} \rho \sum_{i}\left(\frac{\partial C_{L}}{\partial \alpha}\right)_{i} A_{i}\left\|\vec{v}_{c_{i}}\right\|\left(\vec{v}_{c_{i}} \cdot \vec{n}_{i}\right) \vec{n}_{i}
$$

where the summation operates on lifting surfaces such as keel, rudders, and the ship itself. Each surface $\left(S_{i}\right)$ is defined by its lift curve slope $\partial C_{L} / \partial \alpha$, its area $A$, and the position $\left(x_{c}, y_{c}, z_{c}\right)$ of the centre of pressure in the body-fixed frame.

\subsubsection{Equations of Motion}

Finally, given the contact forces $\mathbf{F}_{C}$, the equation of ship motion can be written in the bodyfixed reference frame with the following general form:

$$
\mathbf{M} \dot{\mathbf{y}}+\mathbf{G} \mathbf{y}=\left[\mathbf{F}_{W}+\mathbf{F}_{H}+\mathbf{F}_{V}\right](\mathbf{y}, \mathbf{x})+\mathbf{F}_{C},
$$


where the total mass matrix is

$$
\mathbf{M}=\mathbf{M}_{R B}+\mathbf{M}_{A}
$$

and where the gyroscopic matrix is

$$
\mathbf{G}=\mathbf{G}_{R B}+\mathbf{G}_{A}
$$

During the integration of (3.15), the fact that the forces and moments depend on the position and the attitude of the body in the earth-fixed reference frame is a difficulty because $\int_{0}^{t} \mathbf{y} d \tau$ has no physical interpretation. Therefore, following relation (3.5), it is necessary to apply the transformation operator $\mathbf{J}$ before integration of the earth-fixed components and of the Eulerian angles. Then, the integration algorithm becomes

$$
\begin{aligned}
& \dot{\mathbf{y}}_{n+1}=\mathbf{M}^{-1}\left[-\mathbf{G} \mathbf{y}+\mathbf{F}_{W}+\mathbf{F}_{H}+\mathbf{F}_{V}+\mathbf{F}_{C}\right]_{n+1}, \\
& \mathbf{y}_{n+1}=\mathbf{y}_{n}+\frac{1}{2}\left(\dot{\mathbf{y}}_{n+1}+\dot{\mathbf{y}}_{n}\right)\left(t_{n+1}-t_{n}\right), \\
& \mathbf{x}_{n+1}=\mathbf{x}_{n}+\frac{1}{2}\left(\mathbf{J}_{n+1} \mathbf{y}_{n+1}+\mathbf{J}_{n} \mathbf{y}_{n}\right)\left(t_{n+1}-t_{n}\right) .
\end{aligned}
$$

Conventionally, the initial condition at $t_{1}=0$ is such that the position, attitude, and velocities derivatives are null:

$$
\dot{\mathbf{y}}_{1}=\mathbf{x}_{1}=0 \text {. }
$$

Because the hydrodynamic and gyroscopic forces as well as the transformation operator $\mathbf{J}$ depend on $\mathbf{y}$ and $\mathbf{x}$, relations (3.27) are iterated until the variations of the velocity derivatives $\dot{\mathbf{y}}_{n+1}$ converge.

\section{Ship Collision Analysis Tool}

\subsection{Analysis Procedure}

In order to analyze collision events where both the striking and struck vessels may be damaged, a C++ program called SHARP has been developed. In this program, subroutines calculating internal mechanics are coupled with the adaptive version of MCOL presented in Section 3. The input parameters, defined using a user friendly graphical interface (Figure 8), are data on the structural design of the struck ship, dimensions of the striking bow, and data of one or several collision scenarios describing the striking location, the collision angle, and the velocities of both struck and striking vessels.

As shown in the flow chart of the developed program presented in Figure 10, the crushing force is determined using the superelement method and allows for calculating roll, yaw, and pitch moments at the struck and striking ships centre of gravity. Crushing resistance $\mathrm{F}_{\mathrm{C}}$ and corresponding roll, yaw, and pitch moments are then transmitted to MCOL program, which solves (3.27) and returns new acceleration, velocity, and position of each ship. 


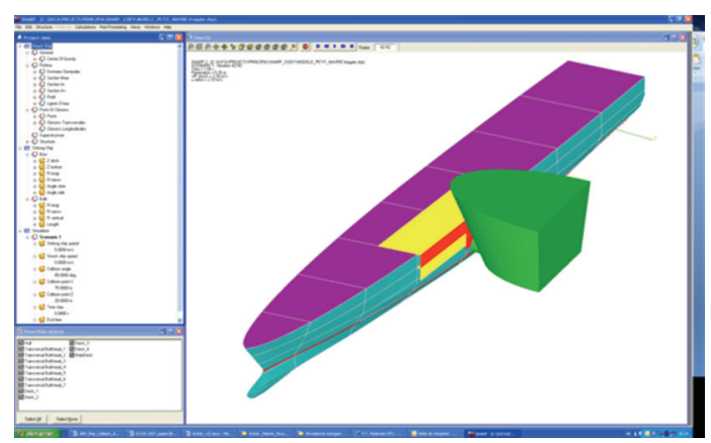

Figure 8: Graphical user's interface.

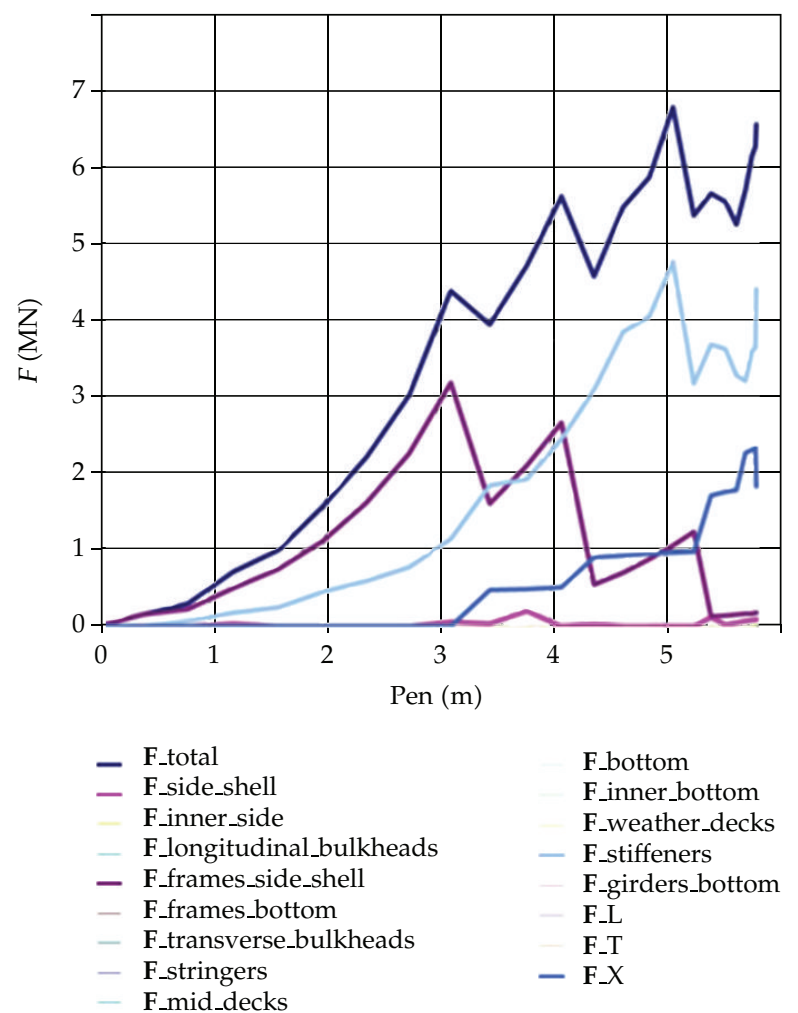

Figure 9: Example of substructures crushing forces postprocessing.

When the sway velocity of the struck ship at the impact point $\mathbf{V}_{2}$ becomes higher than the projected surge velocity of the striking ship $\mathbf{U}_{1}$, the program stops and the graphical user's interface allows for postprocessing simulation results like

(i) the crushing forces and the internal energies calculated for each kind of substructure (an example of plot is given in Figure 9),

(ii) the hydrodynamic forces acting on the ship side and overall energy balance,

(iii) graphical views of the collision event as shown in Figure 8, where the impacted and destroyed substructures are highlighted. 


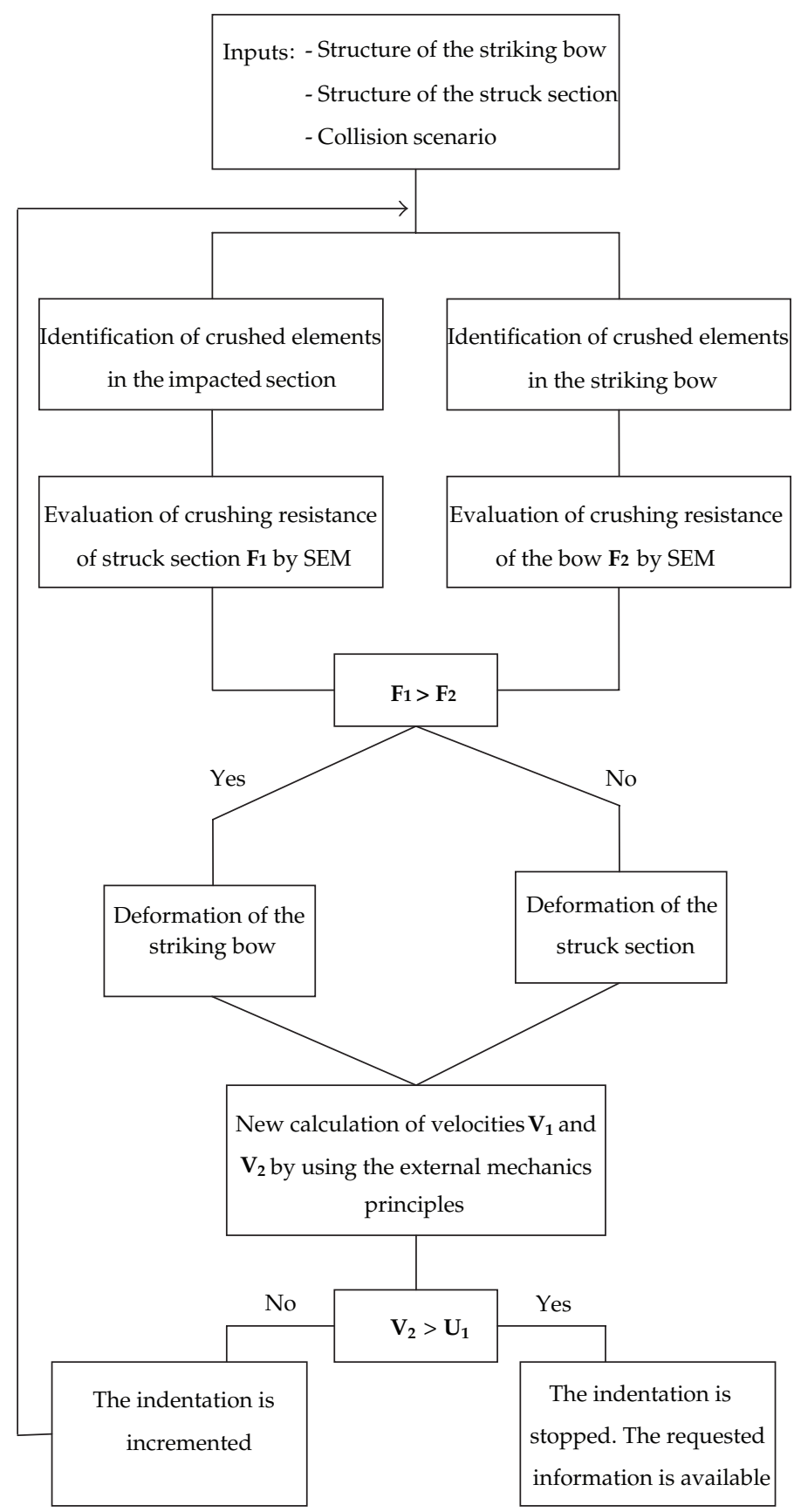

Figure 10: Flow chart of the collision analysis procedure.

\subsection{Comparison with Finite Element Results}

In order to validate the developed program, several impact simulations have been performed for different struck ships like container vessel, frigate, and FPSO, and resulting penetrations and crushing forces have been compared with those obtained using nonlinear 


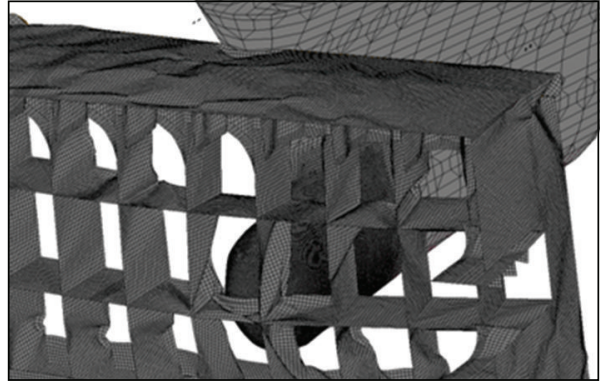

(a)

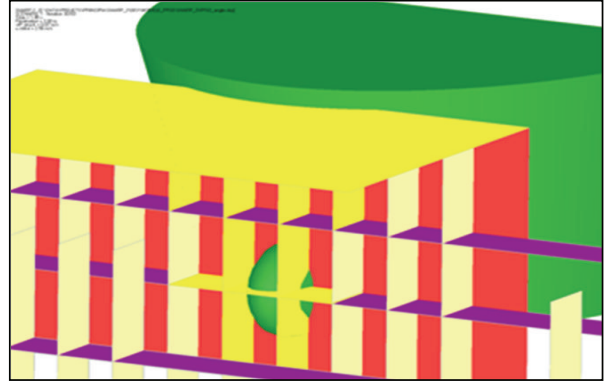

(b)

Figure 11: Struck ship damage postprocessing of finite element and SHARP simulations.

Table 1: Ships main characteristics.

\begin{tabular}{lcc}
\hline & FPSO & Crude oil carrier \\
\hline Length & $280 \mathrm{~m}$ & $200 \mathrm{~m}$ \\
Breadth & $60 \mathrm{~m}$ & $48 \mathrm{~m}$ \\
Depth & $33 \mathrm{~m}$ & $25 \mathrm{~m}$ \\
Draft & $23 \mathrm{~m}$ & $13 \mathrm{~m}$ \\
DWT & $350,000 \mathrm{t}$ & $140,000 \mathrm{t}$ \\
\hline
\end{tabular}

LS-DYNA/MCOL finite element calculations [20,30]. One of these comparisons is illustrated in Figure 11, where a 350,000 DWT FPSO side is struck by a 140,000 DWT crude oil carrier at a velocity of 1.5 knots. The FPSO is at rest and is collided perpendicularly between two transverse frames. The main characteristics of both ships are listed in Table 1.

SHARP calculations using rigid and deformable striking ship are performed. In finite element and SHARP simulations, ruptures of FPSO side shell and longitudinal bulkheads are modeled using erosive plastic behavior law for steel material. When the plastic strain calculated in shell elements (resp. superelements) exceeds a threshold value of $20 \%$, their crushing resistance is set to zero. Penetration and crushing force time histories are plotted in Figure 12. Even if there are some discrepancies between SHARP and finite element crushing force evolution (due to radically different formulations), the final penetration into struck ship is well assessed by the analytical formulation-based tool. Figure 12(a) shows also that the resulting penetration into struck ship may double when the striking ship is considered as rigid.

\section{Application Examples}

SHARP program is used advantageously to investigate the sensitivity of some collision parameters, and we present in this section numerical analyses of the effect of

(i) the hydrodynamic forces,

(ii) the vertical and longitudinal striking location along the hull girder for different striking ship surge velocities,

(iii) the angle between struck and striking vessel at the beginning of the impact,

(iv) the struck ship initial surge velocity. 


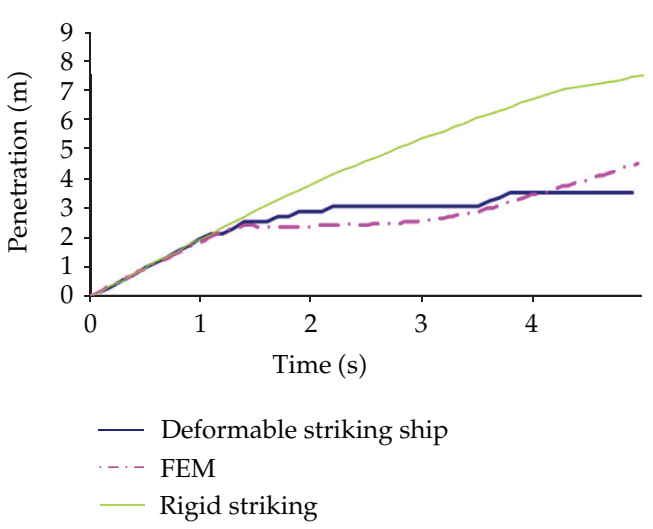

(a) Penetration $(\mathrm{m})$

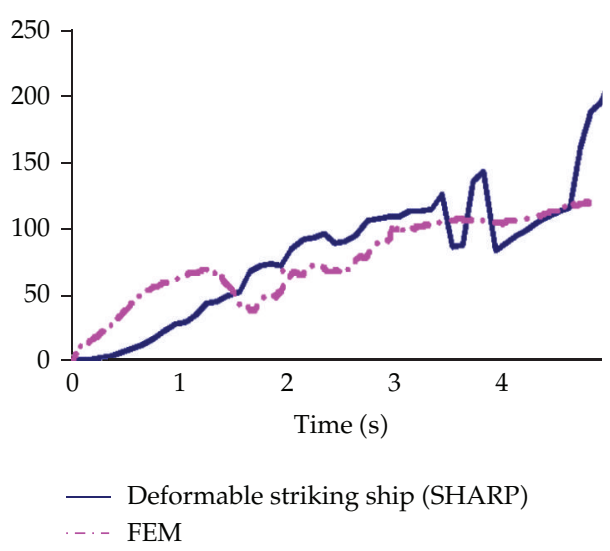

(b) $\mathrm{F}(\mathrm{MN})$

Figure 12: Time histories of penetration and total crushing force.

Table 2: Ships main characteristics.

\begin{tabular}{lcc}
\hline & Crude oil carrier & Container vessel \\
\hline Length & $234 \mathrm{~m}$ & $221.5 \mathrm{~m}$ \\
Breadth & $42 \mathrm{~m}$ & $32.2 \mathrm{~m}$ \\
Depth & $21 \mathrm{~m}$ & $24 \mathrm{~m}$ \\
Draft & $14.9 \mathrm{~m}$ & $11.5 \mathrm{~m}$ \\
DWT & $105,400 \mathrm{t}$ & $40,000 \mathrm{t}$ \\
\hline
\end{tabular}

\subsection{Influence of Hydrodynamic Forces}

As a first application example, let us consider a 40,000 DWT container vessel struck by a 105,400 DWT crude oil carrier. The main characteristics of these vessels are presented in Table 2 . The scantling of both ships and the striking bow geometry may be found in [25]. The metacentric height of the container vessel is equal to $2.5 \mathrm{~m}$, and the roll period is $3.3 \mathrm{~s}$.

In the collision scenario illustrated in Figure 13(a), the crude oil carrier strikes the container side at midheight and midship with an initial velocity of $3 \mathrm{~m} / \mathrm{s}$. The importance of the external dynamics calculation is illustrated in Figure 14, where the crushing force obtained without using MCOL module (external dynamics is ignored and the container vessel is then supposed to be fixed) is compared to the crushing force obtained using the complete collision tool (the 6 degrees of freedom rigid body ship movements are then simulated).

In such collision case, the impacted container vessel is subjected to a large sway movement during and after the impact. Therefore, a part of impact energy is converted into struck ship kinetic energy and the resulting crushing force peak is much reduced comparing to the fixed struck ship case. Resulting indentation of rigid cargo into deformable container varies from 11 meters without MCOL to 7 meters with MCOL.

In the second collision scenario illustrated in Figure 13(b), the cargo bulb considered as rigid strikes the upper part of the container side. The impact leads to a roll movement of the struck ship, illustrated by the significant virtual work of hydrostatic restoring forces shown in Figure 15(a). The struck ship roll movement obviously influences the crushing 


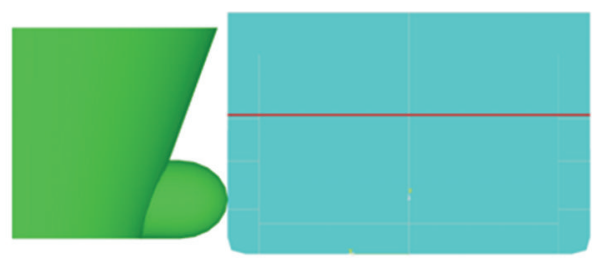

(a) Impact at midheight

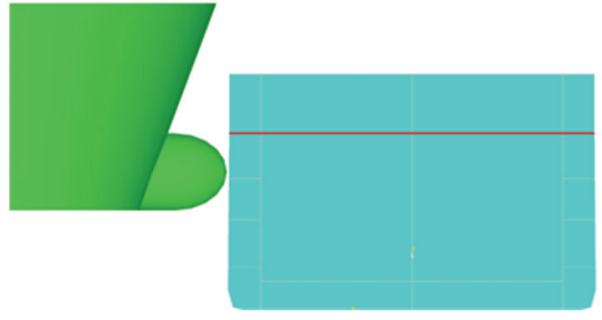

(b) Impact on upper part

Figure 13: Crude oil carrier against container vessel: collision scenarios.

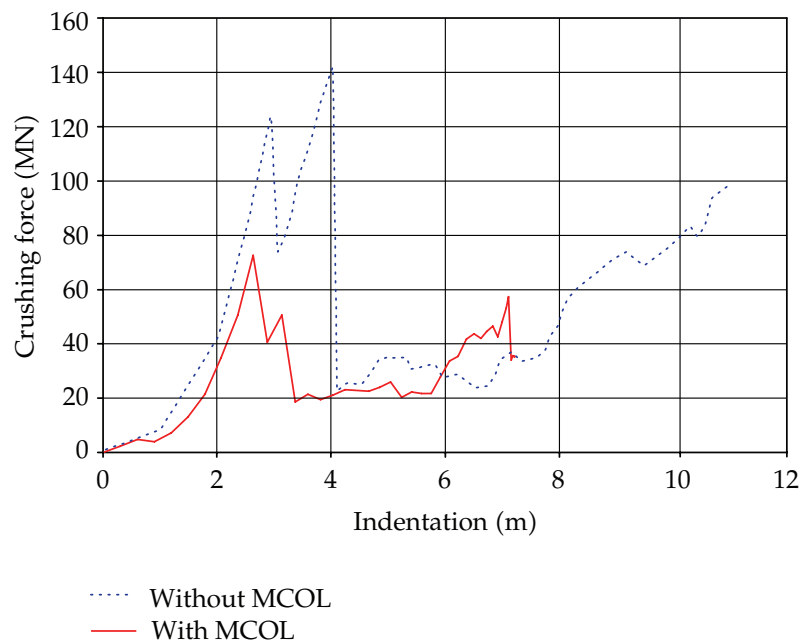

Figure 14: Crushing force with and without MCOL.

mechanism, and a part of this work is used at a later stage for further crushing of structures. This phenomenon will be highlighted in Section 5.2. Note also that the energy dissipated by viscous forces becomes significant at the end of the impact, when the roll and sway velocities of the struck ship increase.

In the third collision scenario, the cargo strikes the container side at midheight (Figure 13(a)) but near the stern of the ship. The impact point is located at 100 meters from the container centre of gravity, and this impact scenario leads to a large yaw motion of the struck ship. As shown in Figure 15(b), the corresponding wave force virtual work (dissipated energy) represents about $15 \%$ of the total energy. Note that hydrostatic restoring and viscous forces remain small in this case.

\subsection{Sensitivity to Longitudinal and Vertical Striking Location}

We now investigate whether it is important to model in detail the variation of the contact point along the length of the hull. To do this, we use SHARP program to model a 6000 DWT passenger ship impacted by a 6300 DWT dry cargo vessel (Figure 16(a)). The main 


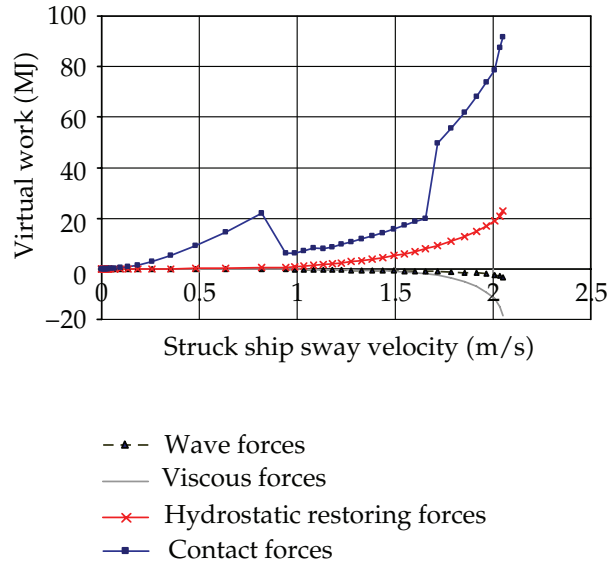

(a) Struck ship roll movement

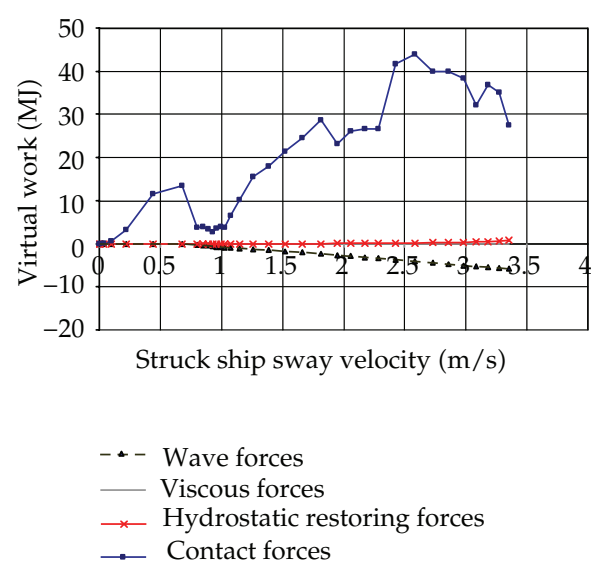

(b) Struck ship yaw movement

Figure 15: Virtual work of involved hydrodynamic forces.

Table 3: Ships main characteristics.

\begin{tabular}{lcc}
\hline & Striking cargo & Struck passenger ship \\
\hline Length & $168 \mathrm{~m}$ & $150 \mathrm{~m}$ \\
Breadth & $20 \mathrm{~m}$ & $20 \mathrm{~m}$ \\
Depth & $15 \mathrm{~m}$ & $13 \mathrm{~m}$ \\
Draft & $6.8 \mathrm{~m}$ & $5 \mathrm{~m}$ \\
DWT & $6,300 \mathrm{t}$ & $6,000 \mathrm{t}$ \\
\hline
\end{tabular}

characteristics of these vessels are shown in Table 3. The metacentric height of the passenger ship is equal to $1 \mathrm{~m} 88$ and the roll period is equal to $4.4 \mathrm{~s}$.

The striking points are located between the main transverse bulkheads. The collision is again a right-angle collision, where the struck vessel has zero speed. We impose to the striking vessel a velocity of 3, 5, or 7 knots. In Figure 16(b), the penetration into the passenger ship is plotted as a function of the striking location. Resulting curves are very similar to those obtained by Lützen et al. [19] and show the consequence of the struck ship yaw movement, that is, most energy has to be absorbed around midships.

In order to show the opportunity of using a $3 \mathrm{D}$ external dynamic calculation, the sensitivity to vertical striking location and resulting struck ship rolling movement is also studied. As shown in Figure 17, the cargo vessel is now assumed to strike perpendicularly the aft part of the passenger ship at different vertical positions varying from 8 to $14 \mathrm{~m} / 0 \mathrm{H}$. The impact velocity of the striking vessel is 20 knots and collision occurs on the first transversal bulkhead.

The evolution of the damage penetration for different vertical impact locations is presented in Figure 18. Figure 19 shows also the resulting rolling and sway movements for both impact configurations shown here. The penetration increases when the impact occurs between 2 decks and decreases when the impact point gets close to a deck. Above $13.25 \mathrm{~m} / 0 \mathrm{H}$, the struck ship weather deck is impacted right from the beginning and a large increase of the resulting rolling angle may be observed (see Figure 19(b)). As written in the previous section, this roll movement influences the crushing mechanism and a part of the 


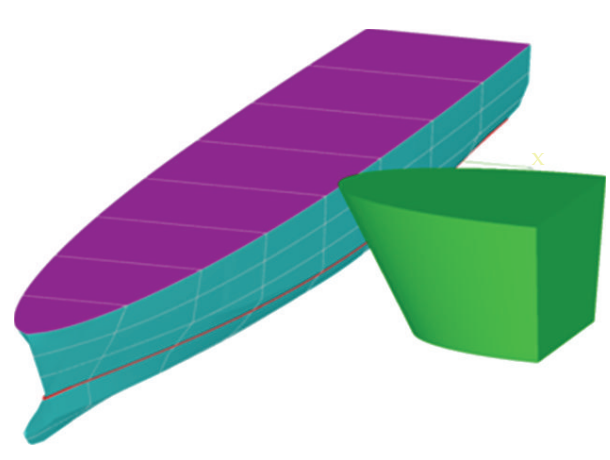

(a) View of involved ships

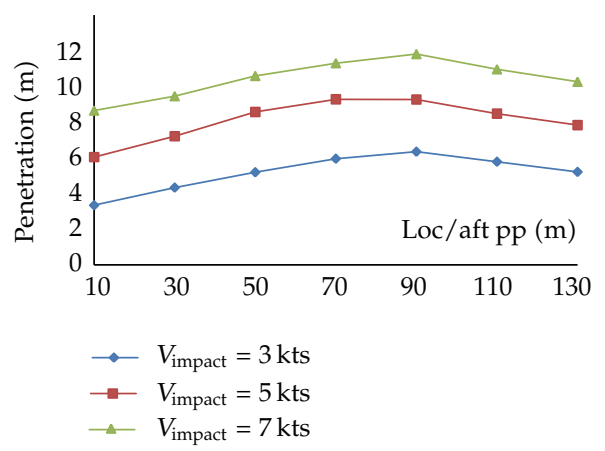

(b) Penetration (m)

Figure 16: Dry cargo vessel against passenger ship: sensitivity to longitudinal impact location.

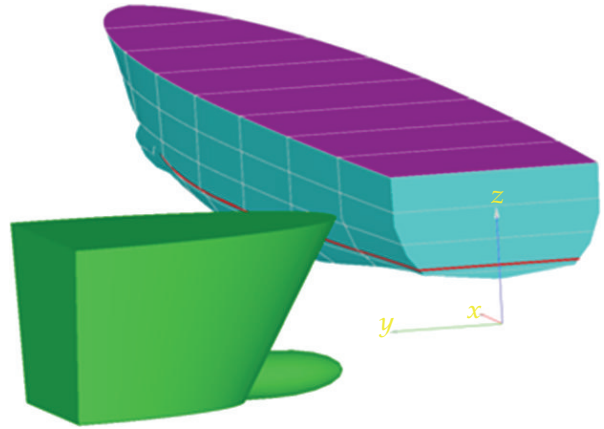

(a) Impact at $8 \mathrm{~m} / 0 \mathrm{H}$

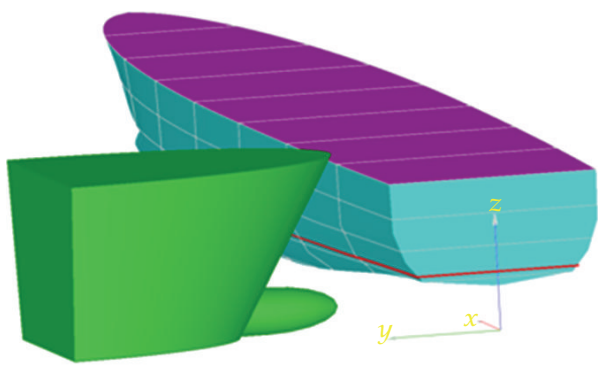

(b) Impact at $14 \mathrm{~m} / 0 \mathrm{H}$

Figure 17: Vertical impact sensitivity analysis: varying draught of striking vessel.

work of hydrostatic restoring forces is used for further crushing of the structure, leading to a larger penetration into the struck ship. For vertical impacts located below the weather deck, the resulting struck ship external dynamics is rather governed by a sway movement (Figure 19(a)), which leads to lower indentation.

\subsection{Sensitivity to Impact Angle and Struck Ship Surge Velocity}

The sensitivity to impact angle is then studied by considering the collision between the dry cargo vessel and the passenger ship presented in the previous section. The impact angle $\beta$ varies from $30^{\circ}$ to $150^{\circ}$ and collisions for two longitudinal impact locations are investigated. In the first configuration, the cargo vessel impacts the passenger ship on a bulkhead located near amidships, at $60 \mathrm{~m} / \mathrm{aft}$ PP (Figure 20(a)). In the second one, the passenger ship is struck between the aft and the first transversal bulkheads, at $10 \mathrm{~m} / \mathrm{aft}$ PP. For both configurations, the rigid cargo vessel impact velocity is equal to 7 knots and the struck ship is initially at rest.

The struck ship damage penetration is plotted in Figure 20(b) as a function of the impact angle. The first impact point is located near the struck ship center of gravity, the obtained curve is as expected symmetric $/ 90^{\circ}$ impact, and the maximum indentation is observed for $65^{\circ}$ and $115^{\circ}$ impact angles. On the other hand, when collision occurs near the 


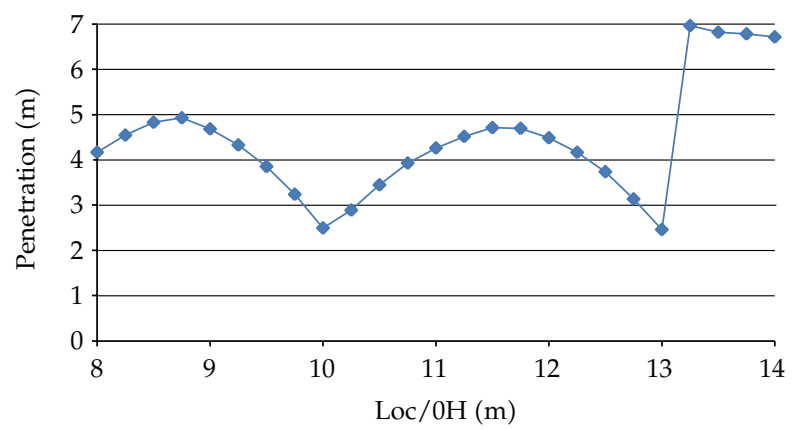

Figure 18: Dry cargo vessel against passenger ship: sensitivity to vertical impact location.

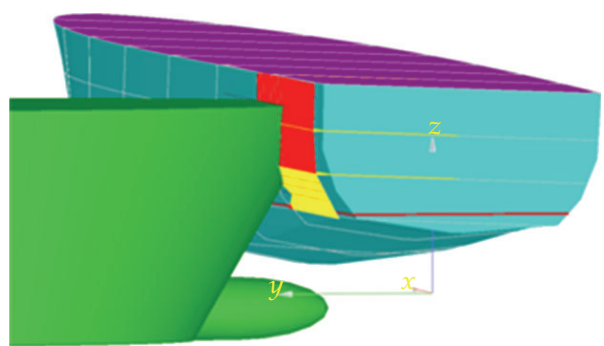

(a) Impact at $8 \mathrm{~m} / 0 \mathrm{H}$ : sway movement

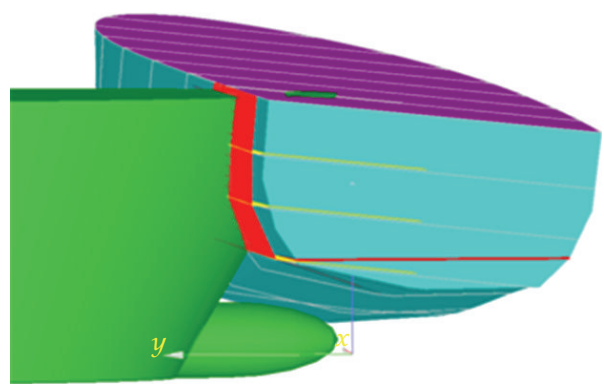

(b) Impact at $14 \mathrm{~m} / 0 \mathrm{H}$ : rolling movement

Figure 19: Vertical impact sensitivity: resulting struck ship sway and rolling movements.

aft bulkhead, the passenger ship sway movement is more import and the ship "escapes" from striking bow for impact angles higher than $130^{\circ}$, which leads of course to lower indentation.

In Figure 21, the extent of longitudinal damage is plotted as a function of impact angle for the first impact longitudinal location, that is, near amidships. It is observed that damage lengths are largest for collision angles of approximately $60^{\circ}$ and $120^{\circ}$. Brown reported in [21] such damage length calculations and obtained similar results, even if the dissymmetry of the curves presented by Brown may be explicated by the fact that the different studied struck ships had nonzero surge velocity.

The same application example is used to study the influence of the struck ship surge velocity $\mathbf{U}_{2}$. The passenger ship, with surge velocity varying from 0 to $20 \mathrm{knots}$, is impacted perpendicularly near a transversal bulkhead located at $84 \mathrm{~m} /$ aft PP (Figure 22(a)). The evolution of the penetration into the struck ship is plotted in Figure 22(b) for 3, 5, and 7 knots striking ship impact velocities. The results are again similar to those obtained in [21], and, as observed by Brown, it appears that the penetration is less sensitive to struck ship speed.

\section{Conclusion}

In the ship collision analysis tool described in this paper, the upper bound method has been used to assess the damage of struck and striking vessels. Based on an adaptive splitting procedure of the struck ship side and the striking ship bow, the internal mechanics solver has 


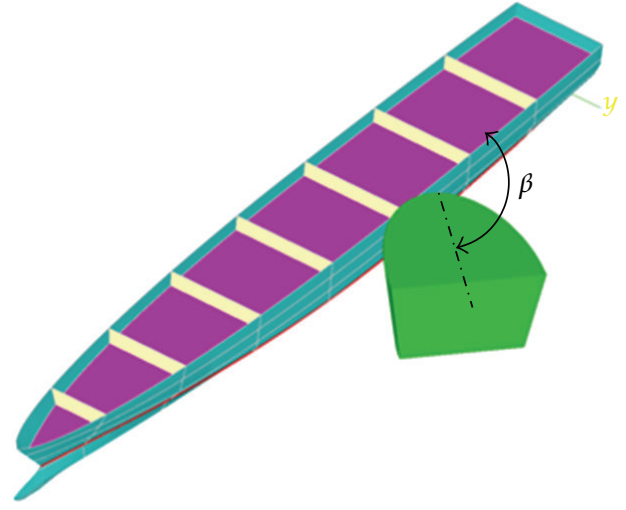

(a) View of collision scenario (1st config.)

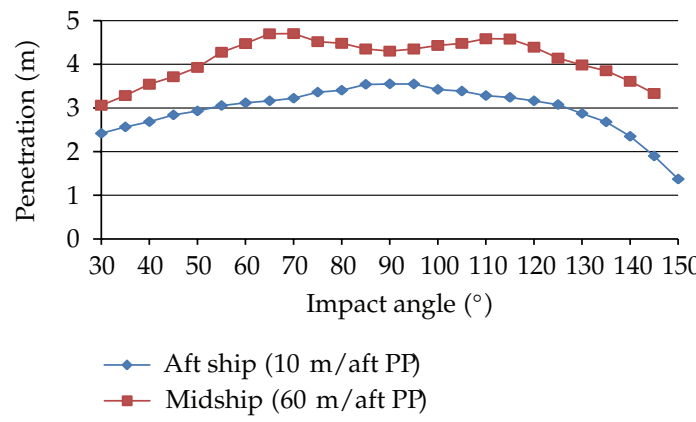

(b) Penetration (m)

Figure 20: Sensitivity of damage penetration to impact angle.

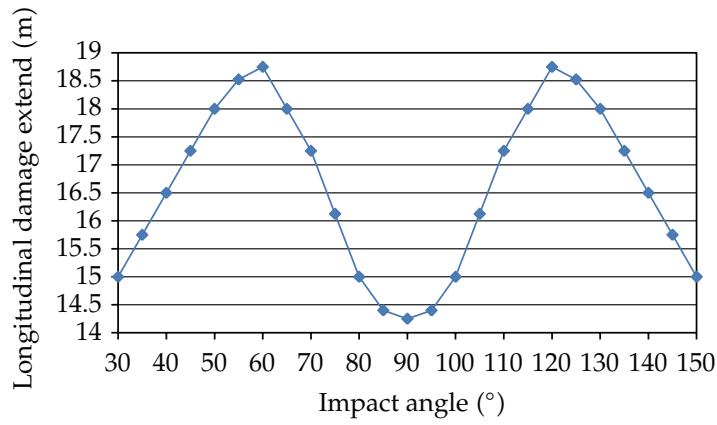

Figure 21: Sensitivity of longitudinal damage extent to impact angle.

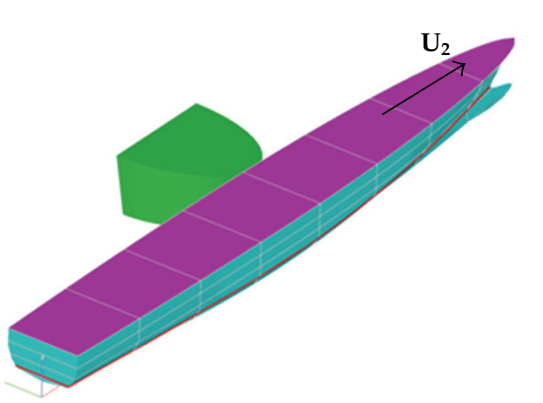

(a) View of involved ships

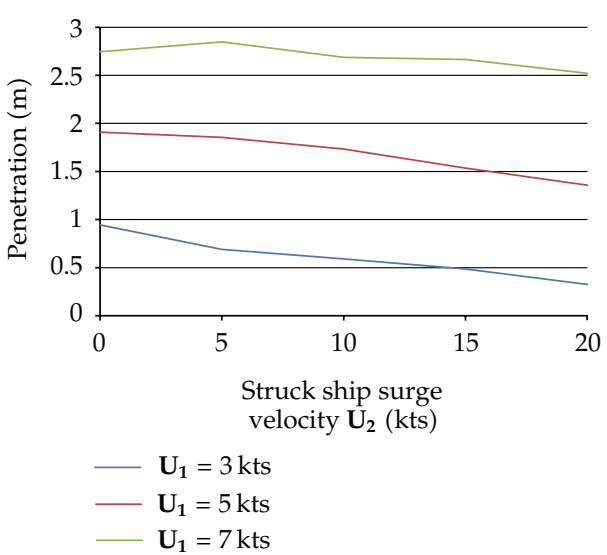

(b) Penetration (m)

Figure 22: Sensitivity of damage penetration to struck ship surge velocity. 
been coupled with the large rotational rigid body program MCOL, which solves the external dynamics by taking into account hydrodynamic loads: added mass inertia forces, hydrostatic restoring forces, wave effect and viscous damping forces.

The importance of external dynamics is shown by comparing a simulation without MCOL with a complete simulation. Moreover, when the struck ship is submitted to a large rolling movement, the importance of hydrostatic restoring forces and viscous damping forces is pointed out. When a large yaw movement occurs, the contribution of wave damping effects may also become significant.

By using the developed analytical tool, which mixes internal and 3D external dynamics, different crushing scenarios including oblique collisions are studied. Sensitivity analysis to longitudinal impact location leads to penetration versus longitudinal impact location curves similar to those obtained by Lützen et al. [19]. Sensitivity to impact vertical location is also investigated for a $20-\mathrm{knots}$ collision, and resulting penetrations are shown to be strongly dependent of the struck ship rolling movement. This result shows clearly the opportunity of using in some cases a 3D external dynamic calculation.

Such a rapid prediction tool is then used advantageously to study the sensitivity of other collision parameters like impact angle and struck ship surge velocity. Resulting damage penetrations or longitudinal damage length curves are similar to those presented by Brown in [21].

Another application of SHARP tool could be to analyze circumstances around collision accidents, which have already taken place. Note finally that this simplified analysis approach allows for decreased time-consuming simulations (a few seconds) comparing to finite element simulations (several days in some cases). Coupled with a user-friendly graphical interface, SHARP program is a useful tool to optimize ship scantling against collision.

\section{Acknowledgments}

This work has been performed in the frame of the joint industry project "SHARP2" (Ship Hazardous Aggression Research Program). The aim of SHARP2 is to deliver a dedicated software and associated guideline for marine structure for resistance to aggression damage: ship collision and collision against icebergs. ICAM and PRINCIPIA would like to thank DCNS and BUREAU VERITAS for their technical participation in defining the scope of work and their financial support to SHARP2 project.

\section{References}

[1] P. T. Pedersen, "Review and application of ship collision and grounding analysis procedures," Marine Structures, vol. 23, no. 3, pp. 241-262, 2010.

[2] U. V. Minorsky, "An analysis of ship collisions with reference to nuclear power plants," Journal of Ship Research, vol. 3, pp. 1-4, 1959.

[3] T. Wierzbicki and J. Culbertson-Driscoll, "Crushing damage of web girders under localized static loads," Journal of Constructional Steel Research, vol. 33, no. 3, pp. 199-235, 1995.

[4] G. Wang and H. Ohtsubo, "Deformation of ship plate subjected to very large load," in Proceedings of the 16th International Conference on Offshore Mechanics and Arctic Engineering (OMAE '97), vol. 2, pp. 173-180, 1997.

[5] B. C. Simonsen, "Ship grounding on rock-I. Theory," Marine Structures, vol. 10, no. 7, pp. 519-562, 1997.

[6] S. M. Zhang, The mechanics of ship collisions, Ph.D. Thesis, Department of Naval Architecture and Offshore Engineering, Technical University of Denmark, Lyngby, Denmark, 1999. 
[7] L. Hong and J. Amdahl, "Crushing resistance of web girders in ship collision and grounding," Marine Structures, vol. 21, no. 4, pp. 374-401, 2008.

[8] G. Wang, "Some recent studies on plastic behavior of plates subjected to large impact loads," Journal of Offshore Mechanics and Arctic Engineering, vol. 124, no. 3, pp. 125-131, 2002.

[9] G. Wang and H. Ohtsubo, "Deformation of ship plate subjected to very large load," Journal of Offshore Mechanics and Arctic Engineering, vol. 119, pp. 173-180, 1997.

[10] G. Wang and H. Ohtsubo, "An upper-bound solution to the problem of plate tearing," Journal of Marine Science and Technology, vol. 1, no. 1, pp. 46-51, 1995.

[11] S. M. Zhang, "Plate tearing and bottom damage in ship grounding," Marine Structures, vol. 15, no. 2, pp. 101-117, 2002.

[12] T. Wierzbicki, "Concertina tearing of metal plates," International Journal of Solids and Structures, vol. 32, no. 19, pp. 2923-2943, 1995.

[13] P. E. Zheng, Theorical analysis of wedge cutting through metal plates, Ph.D. Thesis, Massachusetts Institute of Technology, 1994.

[14] J. K. Paik, Ultimate Limit State Design of Steel-Plated Structures, John Wiley \& Sons, Chichester, UK, 2003.

[15] S. R. Cho and H. S. Lee, "Experimental and analytical investigations on the response of stiffened plates subjected to lateral collisions," Marine Structures, vol. 22, no. 1, pp. 84-95, 2009.

[16] Y. Ueda, S. M. H. Rashed, and J. K. Paik, "Buckling and ultimate strength interaction in plates and stiffened panels under combined inplane biaxial and shearing forces," Marine Structures, vol. 8, no. 1, pp. 1-36, 1995.

[17] J. Amdahl, Energy absorption in ship-platform impact, Ph.D. Thesis, Department of Marine Technology, Norwegian University of Science and Technology, 1983.

[18] Y. Ueda and S. M. H. Rashed, "The idealized structural unit method and its application to deep girder structures," Computers and Structures, vol. 18, no. 2, pp. 277-293, 1984.

[19] M. Lützen, B. C. Simonsen, and P. T. Pedersen, "Rapid prediction of damage to struck and striking vessels in a collision even," in Proceedings of the International Conference of Ship Structure for the New Millennium: Supporting Quality in Shipbuilding, Arlington, TX, USA, 2000.

[20] L. Buldgen, H. Le Sourne, N. Besnard, and P. H. Rigo, "Extension of the super-element method to the analysis of oblique collision between two ships," Marine Structures. In press.

[21] A. J. Brown, "Collision scenarios and probabilistic collision damage," Marine Structures, vol. 15, no. 4-5, pp. 335-364, 2002.

[22] H. Le Sourne, R. Donner, and F. Besnier, "External dynamics of ship-submarine collision," in Proceedings of the International Conference on Collision and Grounding of Ships (ICCGS '01), pp. 137-144, 2001.

[23] N. Jones, Structural Impact, Cambridge University Press, Cambridge, UK, 1997.

[24] P. T. Pedersen, S. Valsgård, D. Olsen, and S. Spangenberg, "Ship impacts: bow collisions," International Journal of Impact Engineering, vol. 13, no. 2, pp. 163-187, 1993.

[25] M. Lützen, Ship collision damage, Ph.D. Thesis, Department of Mechanical Engineering, Technical University of Denmark, 2001.

[26] B. C. Simonsen and H. Ocakli, "Experiments and theory on deck and girder crushing," Thin-Walled Structures, vol. 34, no. 3, pp. 195-216, 1999.

[27] F. H. Imlay, "The complete expressions for added mass of a rigid body moving in an ideal fluid," Tech. Rep. DTMB 1528, David Taylor Model Bassin, Washington, DC, USA, 1961.

[28] R. E. D. Bishop and W. G. Price, "Some comments on present-day ship dynamics," Philosophical Transactions of the Royal Society A, vol. 334, no. 1634, pp. 187-197, 1991.

[29] M. J. Petersen, “Dynamics of ship collisions," Ocean Engineering, vol. 9, no. 4, pp. 295-329, 1982.

[30] Principia, “SHARP 1 user's manual," 2008. 


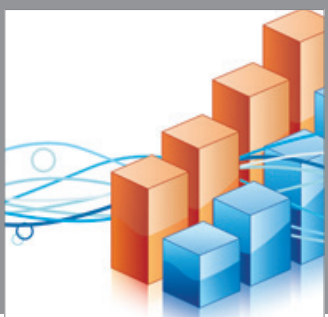

Advances in

Operations Research

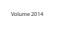

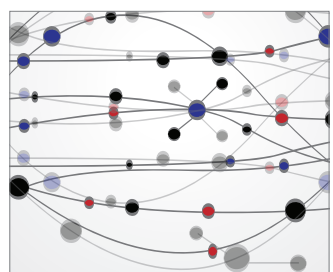

\section{The Scientific} World Journal
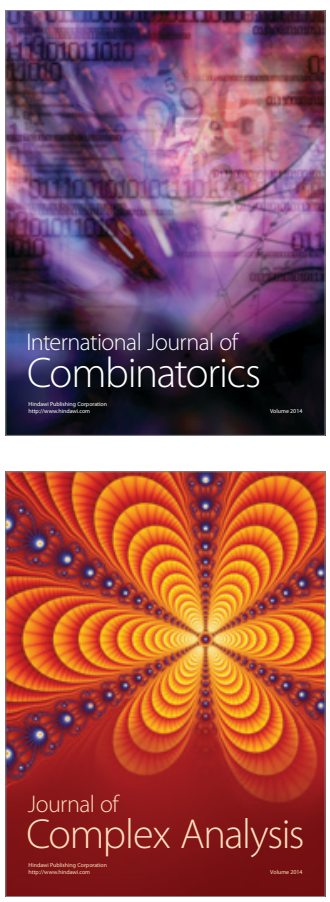

International Journal of

Mathematics and

Mathematical

Sciences
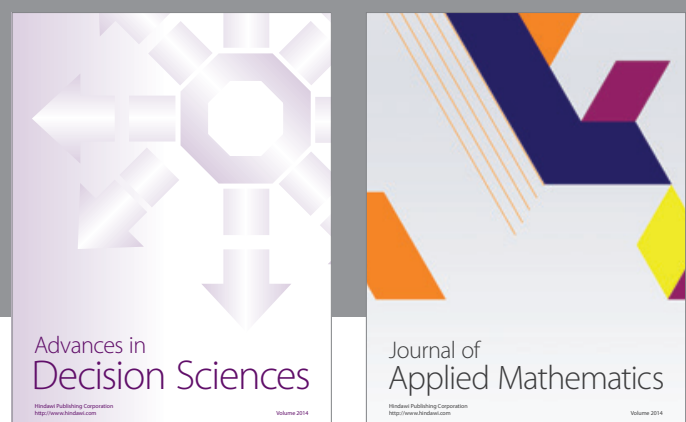

Journal of

Applied Mathematics
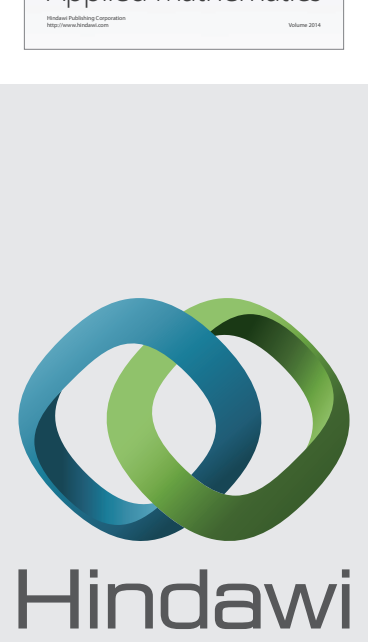

Submit your manuscripts at http://www.hindawi.com
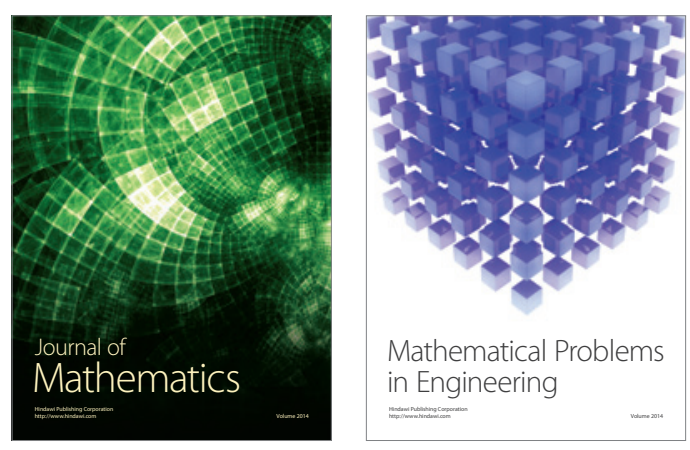

Mathematical Problems in Engineering
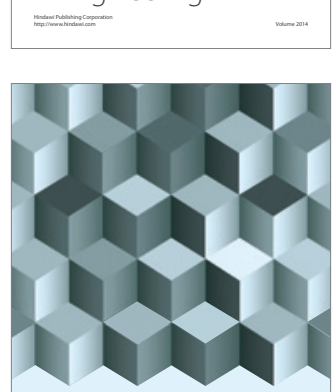

Journal of

Function Spaces
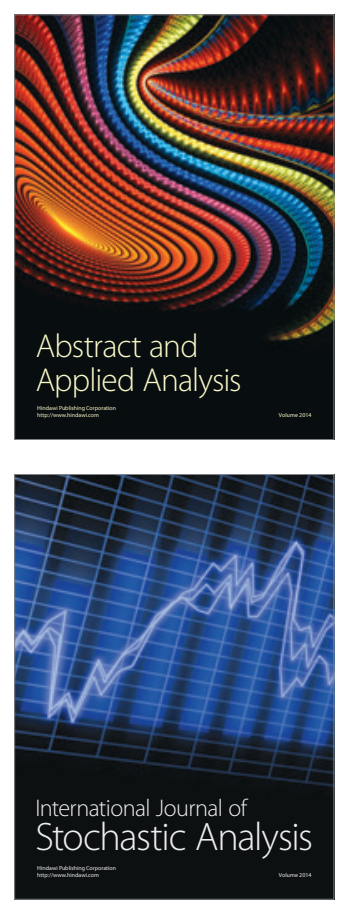

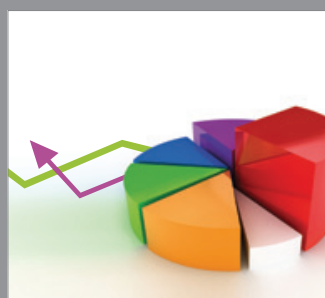

ournal of

Probability and Statistics

Promensencen
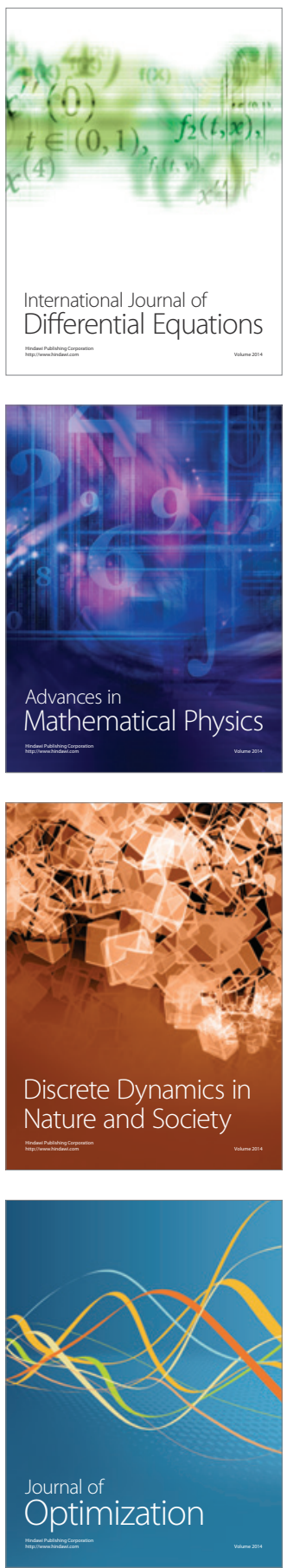